\title{
Obesity alters the expression profile of clock genes in peripheral blood mononuclear cells. Preliminary results
}

Kazunobu Tahira ${ }^{1}$, Takahiro Ueno ${ }^{1,2}$, Noboru Fukuda ${ }^{1}$, Takahiko Aoyama ${ }^{3}$, Akiko Tsunemi ${ }^{1}$, Siroh Matsumoto ${ }^{1}$, Chinami Nagura', Taro Matsumoto ${ }^{4}$, Masayoshi Soma ${ }^{2.5}$, Shigeki Shimba ${ }^{6}$, Yoshiaki Matsumoto ${ }^{3}$

${ }^{1}$ Division of Nephrology, Hypertension and Endocrinology, Department of Medicine, Nihon University School of Medicine, Tokyo, Japan

2Division of Cancer Genetics, Department of Medical Science, Nihon University School of Medicine, Tokyo, Japan

${ }^{3}$ Department of Clinical Pharmacokinetics, College of Pharmacy, Nihon University, Tokyo, Japan

${ }^{4}$ Division of Cell Regeneration and Transplantation, Department of Medical Science, Nihon University School of Medicine, Tokyo, Japan

${ }^{5}$ Division of General Medicine, Department of Medicine, Nihon University School of Medicine, Tokyo, Japan

${ }^{6}$ Department of Health Science, College of Pharmacy, Nihon University, Tokyo, Japan

Submitted: 4 March 2011

Accepted: 17 July 2011

Arch Med Sci 2011; 7, 6: 933-940

DOI: 10.5114/AOMS.2011.26603

Copyright @ 2011 Termedia \& Banach

\begin{abstract}
Introduction: The aim of this study was to investigate the association between the variation in expression profile of clock genes and obesity using peripheral blood mononuclear (PMN) cells.

Material and methods: The subjects comprised 10 obese patients and 10 healthy volunteers. Blood was collected at different time-points during the day and levels of blood sugar, IRI, adiponectin and leptin were determined. Peripheral blood mononuclear cells were sampled, and expression levels of brain and muscle Arnt-like protein-1 (BMAL1), Period (PER)1, PER2, Cryptochrome (CRY)1, CRY2, and REV-ERB $\alpha$ mRNA were quantified.

Results: During the day, the expression levels of BMAL1, CRY1, CRY2 and PER2 genes in PMN cells of the obese group were all significantly higher compared to those in the non-obese group. In addition, expression of BMAL1, CRY1, CRY2 and PER2 genes in PMN cells increased between 12:00 and 21:00 in the obese group. In PMN cells of both groups, PER1 gene expression showed a bimodal pattern, with high expression at 9:00 and 18:00.

Conclusions: Differences were observed in the expression profile variation of clock genes between the obese and non-obese groups. This study reveals the differences in clock gene expression profiles between obese and non-obese subjects, with evidence for two distinct chronotypes, and suggests a contribution of these chronotypes to fat accumulation in humans.
\end{abstract}

Key words: circadian rhythm, biological clock, Per1, Bmal1.

\section{Introduction}

The circadian rhythm is the daily cycle of physiology and behaviour, driven by an endogenous oscillator over the period of each day. This rhythm is controlled by the circadian clock, subject to regulation by the light-dark cycle [1-3]. In mammals, the circadian orchestration of these processes is

\author{
Corresponding author: \\ Prof. Takahiro Ueno \\ Division of Nephrology, \\ Hypertension \\ and Endocrinology \\ Department of Medicine \\ Nihon University School \\ of Medicine \\ 30-1 Oyaguchi-kami \\ Itabashi 173-8610 \\ Tokyo, Japan \\ Phone: 81-3-3972-8111 \\ ext. 2414 \\ Fax: 81-3-3972-1098 \\ E-mail: \\ ueno.takahiro@nihon-u.ac.jp
}


governed by pacemaker cells located within the suprachiasmatic nucleus of the hypothalamus $[4,5]$. Circadian oscillators have also been found to exist not only in the suprachiasmatic nucleus, but also in peripheral tissues [6-10].

Rhythmic transcriptional enhancement in peripheral tissues provides the basic drive to the system though two transcription factors, circadian locomotor output cycles protein kaput (CLOCK), and brain and muscle Arnt-like protein-1 (BMAL1) [11].

The CLOCK-BMAL1 heterodimer directly or indirectly activates the transcription of various clockcontrolled genes. In parallel, the heterodimer also activates the transcription of several clock genes, including Period (Per)1, Per2 and Cryptochrome (Cry)1, Cry2. PER and CRY proteins then translocate back into the nucleus, and inhibit the activity of CLOCK-BMAL1, forming a negative feedback loop $[12,13]$. These clock genes then control the circadian rhythm by regulating the expression of multiple clock-controlled genes [11].

Peripheral adipose tissues have previously been thought to be responsible only for storage of excess energy derived from the diet as fat. In addition to this role, recent studies have revealed that adipose tissue secretes a number of biologically active molecules called adipokines $[14,15]$. The circulating level of one of these adipokines, leptin, exhibits a clear daily variation in animals and humans [9, 16, 17]. Plasma leptin levels are lowest during light periods, and peak during dark periods. Moreover, plasma adiponectin concentrations in non-obese subjects show a $24 \mathrm{~h}$ rhythmic cycle, which is absent in obese subjects $[18,19]$. In addition, altered expression of the clock genes has been reported in the livers of diabetic $(\mathrm{db} / \mathrm{db})$ mice [20].

Shimba et al. used 3T3-L1 adipocytes and BMAL1 knockout mice to demonstrate that induction of BMAL1 gene expression occurs during adipocyte differentiation. This suggests a contribution of BMAL1 to the regulation of adipocyte differentiation and lipogenesis in mature adipocytes [21]. Understanding of clock gene expression has remained limited due to restricted access to the biological material required for gene expression studies.

Rhythmic mRNA expression profiles for human clock genes from oral mucosa and skin biopsies indicate that a peripheral clock is also present in humans [22]. An attractive alternative to tissue biopsies for monitoring human circadian oscillator activity is to use peripheral mononuclear blood cells, in which expression of clock genes has been demonstrated to occur. Expression of circadian clock related genes in peripheral blood cells varies during the day [23]. In this study, the association between daytime variation in genes related to circadian rhythm and obesity was investigated using peripheral blood mononuclear cells.

\section{Material and methods}

\section{Study design}

This study has been approved by and carried out according to the instructions of Nihon University Ethics Committee. Twenty study participants were used and informed consent was obtained. Only male subjects were included to avoid a putative interference between circadian rhythm and the ovarian cycle. Inclusion criteria for the obese group were a body mass index above $25 \mathrm{~kg} / \mathrm{m}^{2}$, and a waist circumference above $85 \mathrm{~cm}$. For the nonobese group a body mass index less than $25 \mathrm{~kg} / \mathrm{m}^{2}$, and a waist circumference of less than $85 \mathrm{~cm}$ were required. Subjects who had experienced either jet lag or shift work during the 2 weeks preceding the experiment, or who had taken psychotropic drugs, were excluded from the study. None of the subjects had a history of stress or psychiatric disease, or were taking medications. Each subject was asked to follow a regular daily routine of wakefulness and sleep before the experiment. Subjects ate breakfast at 09:15, lunch at 12:15 and dinner at 18:15 just after blood sampling. The collection of peripheral blood was performed at 09:00, 12:00, 15:00, 18:00 and 21:00. All subjects followed the same menu for their meals.

Serum leptin, adiponectin, insulin and high-sensitivity C-reactive protein (hs-CRP) levels were determined at 09:00. Plasma lipid, glucose, melatonin, and cortisol levels were determined at each time point. Peripheral blood mononuclear cells were isolated and their levels of BMAL1, PER1, PER2, CRY1, CRY2, REV-ERB $\alpha$ and sterol regulatory element-binding transcription factor 1a (SREBP1a) mRNA were determined by real-time PCR.

Fasting serum insulin was measured by chemiluminescent enzyme immunoassay. Serum hs-CRP was determined by nephelometory. Serum leptin was determined by radioimmunoassay. Serum adiponectin was measured by an enzyme-linked immunosorbent assay.

The homeostasis model assessment (HOMA-IR) index was calculated with the expression: insulin $[\mathrm{mU} / \mathrm{ml}] \times$ blood glucose $[\mathrm{mg} / \mathrm{dl}] / 405$.

\section{Determination of mRNA expression}

Blood samples were collected in heparin tubes, layered on a Ficoll-Paque density gradient (Sigma) and centrifuged at $400 \times \mathrm{g}$ for $30 \mathrm{~min}$ at room temperature to isolate peripheral blood mononuclear cells. Total RNA was isolated from the peripheral blood mononuclear cells and reverse-transcribed as described previously [24]. Real-time quantitative PCR was performed with CDNA that had been diluted 3 times, using TaqMan Universal Master Mix (Applied Biosystems, Foster City, CA), and an ABI 7500 sequence detector (Applied Biosystems) 
according to the manufacturer's instructions. Assayon-Demand primers and probes were purchased from Applied Biosystems, and 18-s rRNA was used for sample normalization. Real-time PCR data were analysed using a standard curve. In all cases, the correlation coefficients for the standard curves were $>0.90$.

\section{Statistical analysis}

Results are shown as the mean \pm standard error of the mean (SEM). The significance of differences between mean values was evaluated by Student's t-test for unpaired data. A $p$ value less than 0.05 was considered significant.

\section{Results}

\section{Subject characteristics}

General characteristics of all participants are summarized in Table I. Obese subjects had significantly higher systolic and diastolic blood pressure compared with non-obese subjects. Serum cholesterol (total and LDL) and triglyceride levels were also significantly higher in obese subjects. In the obese group HOMA-IR was significantly higher compared to the non-obese group (4.08 and 1.22 respectively). Plasma leptin level was significantly higher, and plasma adiponectin level was significantly lower in obese subjects compared to non-obese subjects. The obese subjects in this study displayed common features of obese or metabolic syndrome participants.

\section{Expression profile variation in plasma glucose, triglyceride and free fatty acid levels}

Figure 1 shows the circadian variation in plasma cortisol and melatonin levels of individual subjects in both the obese and non-obese group. Plasma cortisol level reached its acrophase in the morning (Figure $1 \mathrm{~A}-\mathrm{B}$ ). In both groups, plasma melatonin level reached its acrophase at midnight (Figure 1C-D). These data suggest that the subjects' circadian rhythms were maintained. Figure 2 demonstrates circadian variation of plasma glucose (Figure $2 \mathrm{~A}$ ) and free fatty acid levels (Figure 2 B). There was no significant difference in plasma glucose level at any time point between the obese and non-obese groups. The plasma free fatty acid level increased at 09:00 and 18:00. This pattern was seen in both the obese and non-obese groups. However, the plasma free fatty acid levels were significantly higher in the obese subjects at 15:00, 18:00 and 21:00 compared to the non-obese controls.

In the non-obese group, the plasma triglyceride level at each time-point was less than $150 \mathrm{mg} / \mathrm{dl}$, with few exceptions. However, in the obese group, the serum triglyceride level was significantly high-
Table I. Characteristics of the subjects

\begin{tabular}{|c|c|c|}
\hline Parameter & $\begin{array}{c}\text { Non obesity } \\
\left(\mathrm{BMI}<25 \mathrm{~kg} / \mathrm{m}^{2}\right)\end{array}$ & $\begin{array}{c}\text { Obesity } \\
\left(\mathrm{BMI} \geq 25 \mathrm{~kg} / \mathrm{m}^{2}\right)\end{array}$ \\
\hline$n$ & 10 & 10 \\
\hline Height $[\mathrm{cm}]$ & $170.4 \pm 2.0$ & $169.6 \pm 1.4$ \\
\hline Weight [kg] & $63.2 \pm 2.4$ & $92.9 \pm 6.9^{*}$ \\
\hline$W C[\mathrm{~cm}]$ & $73.6 \pm 1.2$ & $101.8 \pm 5.1^{\star}$ \\
\hline $\mathrm{BMI}\left[\mathrm{kg} / \mathrm{m}^{2}\right]$ & $21.7 \pm 0.6$ & $32.2 \pm 2.1^{*}$ \\
\hline Age [year] & $24.1 \pm 1.3$ & $29.6 \pm 1.9^{* *}$ \\
\hline $\mathrm{sBP}[\mathrm{mmHg}]$ & $123.1 \pm 3.7$ & $141.2 \pm 6.9^{\star \star}$ \\
\hline $\mathrm{dBP}[\mathrm{mmHg}]$ & $71.3 \pm 2.8$ & $87.0 \pm 4.0^{*}$ \\
\hline $\begin{array}{l}\text { Total cholesterol } \\
{[\mathrm{mg} / \mathrm{dl}]}\end{array}$ & $179.7 \pm 9.1$ & $215.6 \pm 13.1^{\star *}$ \\
\hline $\begin{array}{l}\text { HDL cholesterol } \\
{[\mathrm{mg} / \mathrm{dl}]}\end{array}$ & $64.8 \pm 3.4$ & $54.7 \pm 2.5^{\star \star}$ \\
\hline $\begin{array}{l}\text { LDL cholesterol } \\
{[\mathrm{mg} / \mathrm{dl}]}\end{array}$ & $100.8 \pm 7.8$ & $131.2 \pm 11.8^{\star *}$ \\
\hline Triglyceride [mg/dl] & $70.7 \pm 12.8$ & $148.6 \pm 16.0^{\star}$ \\
\hline $\mathrm{FFA}[\mathrm{mEq} / \mathrm{l}]$ & $0.42 \pm 0.05$ & $0.40 \pm 0.04$ \\
\hline $\mathrm{IRI}[\mu \mathrm{IU} / \mathrm{ml}]$ & $5.22 \pm 0.51$ & $14.0 \pm 2.9^{\star *}$ \\
\hline Glucose [mg/dl] & $95.0 \pm 1.2$ & $114.4 \pm 10.8$ \\
\hline HOMA-IR & $1.22 \pm 0.12$ & $4.08 \pm 0.96^{\star *}$ \\
\hline $\mathrm{UA}[\mathrm{mg} / \mathrm{dl}]$ & $5.3 \pm 0.4$ & $6.3 \pm 0.4$ \\
\hline $\mathrm{hsCRP}[\mathrm{ng} / \mathrm{ml}]$ & $1006.6 \pm 373.5$ & $2589.4 \pm 871.5$ \\
\hline Leptin $[\mathrm{ng} / \mathrm{ml}]$ & $1.9 \pm 0.4$ & $8.6 \pm 1.9^{\star}$ \\
\hline Adiponectin $[\mu \mathrm{g} / \mathrm{ml}]$ & $8.1 \pm 0.74$ & $5.5 \pm 0.7^{* *}$ \\
\hline
\end{tabular}

Mean $\pm S E,{ }^{*} p<0.01,{ }^{* *} p<0.05$

er. The plasma triglyceride level in the obese group was higher than $200 \mathrm{mg} / \mathrm{dl}$ at 15:00 and 21:00, suggesting postprandial hyperlipidaemia in the obese subjects (Figure 3 ).

\section{Expression profile variation of clock genes in peripheral blood mononuclear cells}

The quantitative gene expression pattern of BMAL1 in human peripheral blood mononuclear cells is shown in Figure $4 \mathrm{~A}$. There was a highly significant variation seen in the expression of BMAL1 in the obese group compared to the non-obese group. In the obese group, expression of BMAL1 was much higher during the day. BMAL1 mRNA was more highly expressed at 15:00 and 21:00, whereas in non-obese subjects BMAL1 mRNA expression displayed only a weak rhythm.

The expression pattern of the clock gene components Cry1, Cry2, Per1 and Per2 in peripheral blood mononuclear cells is shown in Figure 4 B-E. Expression of Cry1 and Cry2 was rhythmic in peripheral blood mononuclear cells from obese subjects but not in those from the non-obese controls. Cry1 

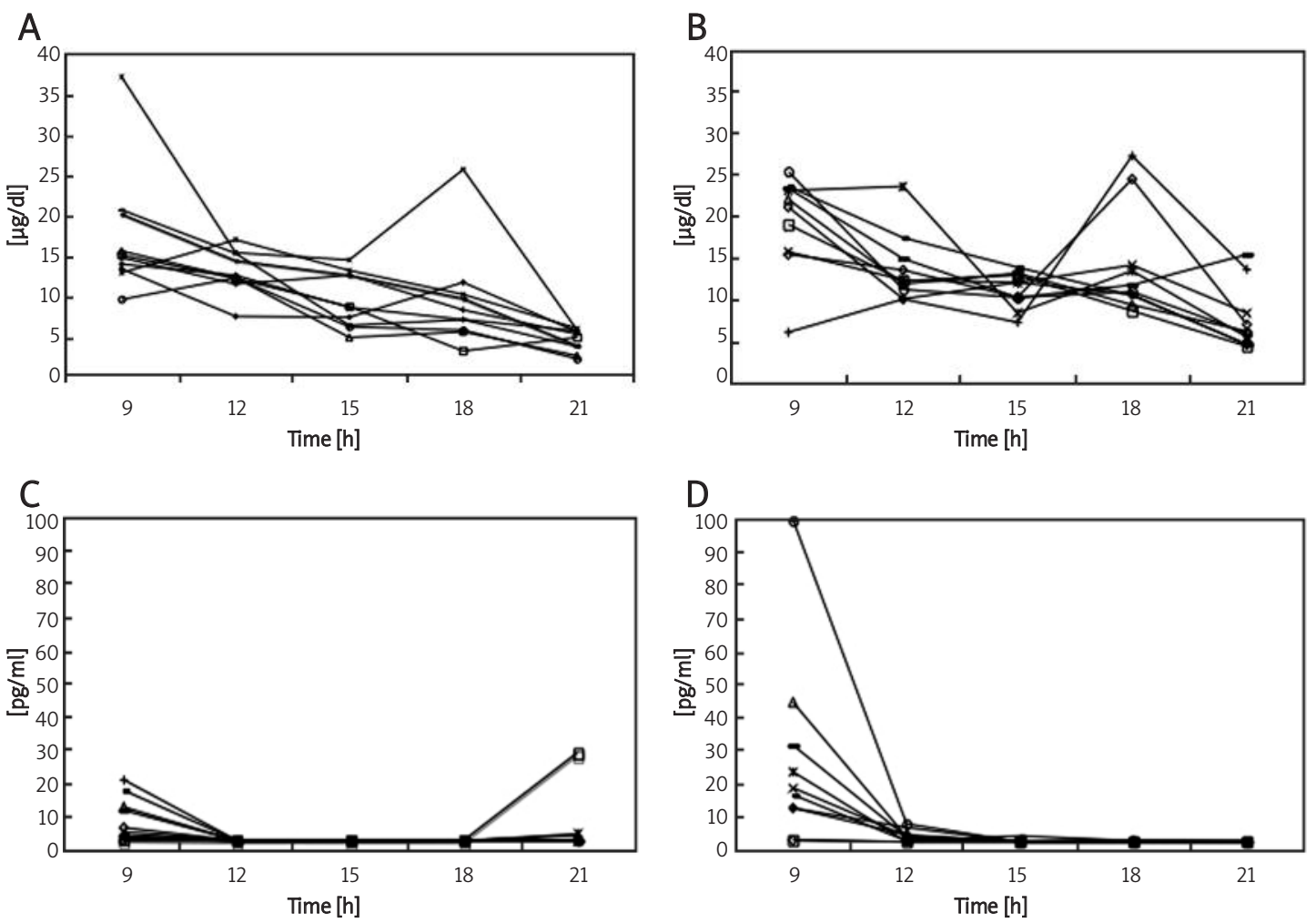

Figure 1. Profile variation of plasma cortisol levels in obese (A) and non-obese controls (B); plasma melatonin levels in obese (C) and non-obese controls (D)
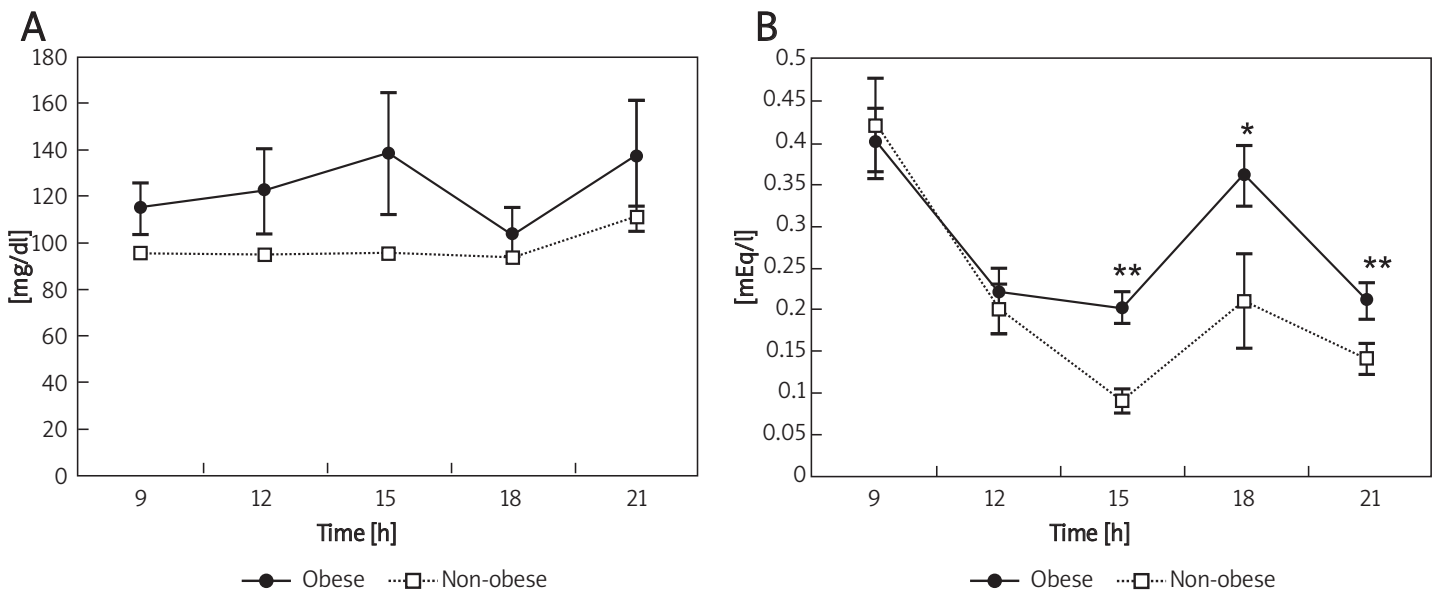

Figure 2. Profile variation of plasma glucose (A) and plasma free fatty acid levels (B) in obese (solid line) and nonobese controls (dashed line)

and Cry2 expression was increased after 15:00 in the obese group. Interestingly, Per1 mRNA expression in peripheral blood mononuclear cells did not show the same sort of expression profile variation as was seen with BMAL1, Cry1 or Cry2, being highest in the morning. The expression pattern of PER1 differed significantly between the obese group and the non-obese controls. However, the circadian variation in expression of Per 2 mRNA was almost the same as that of BMAL1, Cry1 and Cry2.
SREBP1, a transcription factor that targets enzymes involved in regulation of glycolysis, energy production, lipogenesis and cholesterol catabolism, also displays variation of expression in peripheral blood mononuclear cells (Figure 4 F). However, the pattern of SREBP1 expression did not differ significantly between the obese and non-obese groups. Rev-erba, a circadian clock component that forms a negative feedback loop, showed variation of expression in peripheral blood mononuclear cells 
from obese subjects (Figure $4 \mathrm{G}$ ). Expression of Rev-erbo significantly increased after 15:00 in the obese group compared to the non-obese controls, displaying a similar rhythm to BMAL1, Cry1, Cry2 and Per2.

\section{Discussion}

Expression of genes encoding key components of central and peripheral circadian oscillators was analysed in human peripheral blood mononuclear cells from ten obese subjects and ten non-obese controls to investigate the effect of obesity on the human circadian rhythm. This study is the first to describe changes in circadian clock genes in peripheral blood mononuclear cells from obese subjects.

No significant rhythmical variation was found in expression of Bmal1, Cry1, or Cry2 from peripheral mononuclear cells of non-obese control subjects. In contrast, Per1 in non-obese subjects was highly expressed at 9:00, and Per2 displayed a tendency for higher expression at 9:00. These results confirm previous observations on the variation of expression of clock genes in human peripheral blood mononuclear cells in non-obese subjects [23, $25-$ 27]. Previous studies have examined the profile of circadian gene expression from human peripheral blood cells in non-obese subjects. Fukuya et al. reported the absence of circadian oscillation in expression of BMAL1 and Per2 in human mononuclear cells, whereas a significant peak in expression of Per1 was observed at the beginning of the light cycle [25]. Kusanagi et al. recently reported the expression profile of 10 circadian clock genes in peripheral blood mononuclear cells. In their study, Bmal1, Cry1 and Cry2 genes did not show rhythmical changes in expression in human peripheral blood mononuclear cells, whereas robust expression of Per1, Per2 and Per3 genes was observed in the morning [26]. These results suggest that Per1 and Per2 may play a role in regulation of the circadian rhythm in human peripheral mononuclear cells in non-obese subjects.

In obese subjects, Bmal1 gene expression was significantly higher during the day compared to non-obese controls. Bmal1 expression tended to be higher after 15:00, showing obvious rhythmic expression. In this period, plasma triglyceride and glucose levels were also higher in obese subjects compared to the non-obese controls. In mammals, the CLOCK and BMAL1 heterodimer provides the basic drive for circadian rhythmic transcriptional enhancement. The heterodimer directly or indirectly activates transcription of circadian effecter genes $[7,28]$. Because BMAL1/CLOCK is known to play an important role in lipid homeostasis through regulation of circadian activation of potential PPAR response element controlled target genes [29], BMAL1 upregulation during hyperlipidaemic and
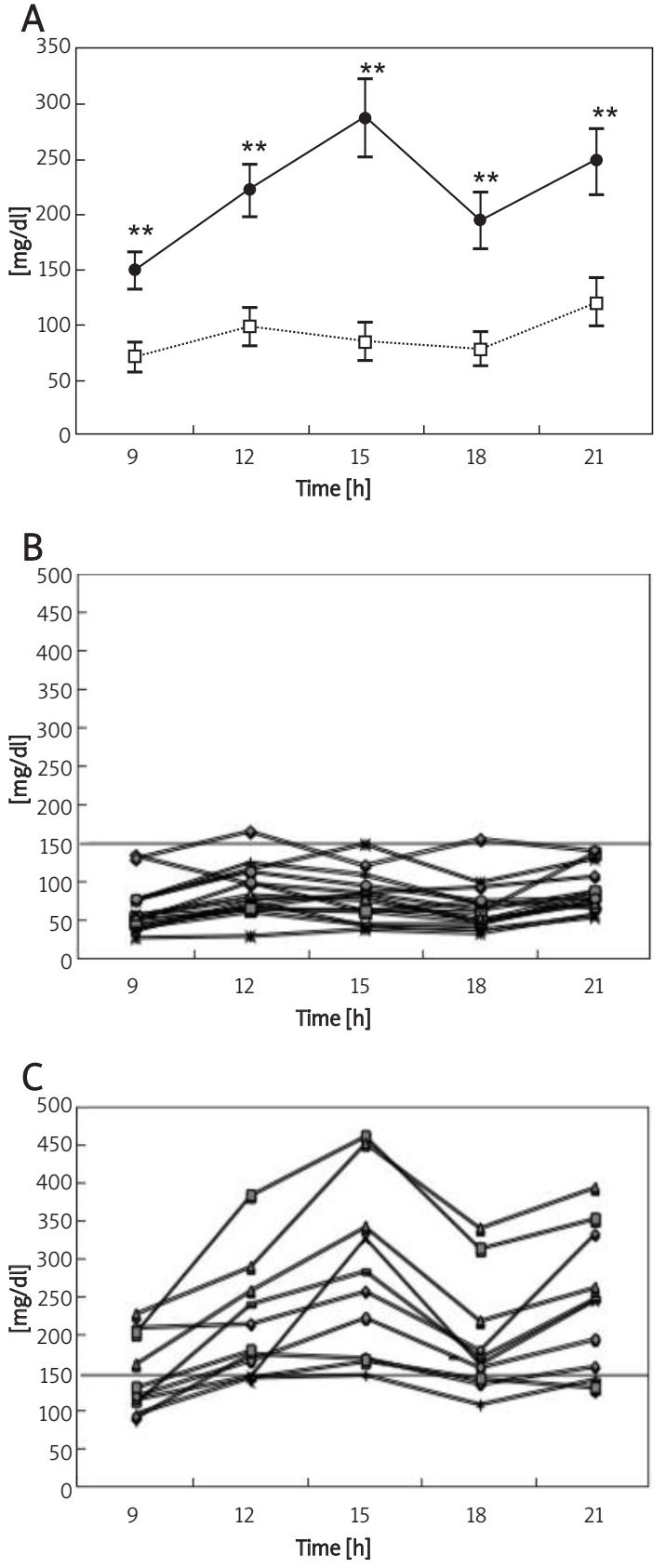

Figure 3. Profile variation of average plasma triglyceride levels in obese (solid line) and non-obese controls (dashed line) (A), and variation of each subject in non-obese (B) and obese controls (C)

hyperglycaemic periods in obese subjects is an important phenomenon that will help to understand lipid metabolism in the development of obesity. The contribution of BMAL1 to the regulation of adipogenesis and adipocyte function has been suggested by many studies. BMAL1 is highly expressed during adipogenesis [21], and Bmal1 deficient mice lack diurnal variation in triglyceride levels [30]. More importantly, mice lacking the circadian regulatory system are obese and develop a metabolic syndrome [31]. Growing evidence suggests a role for BMAL1 in obesity and its related symptoms. 

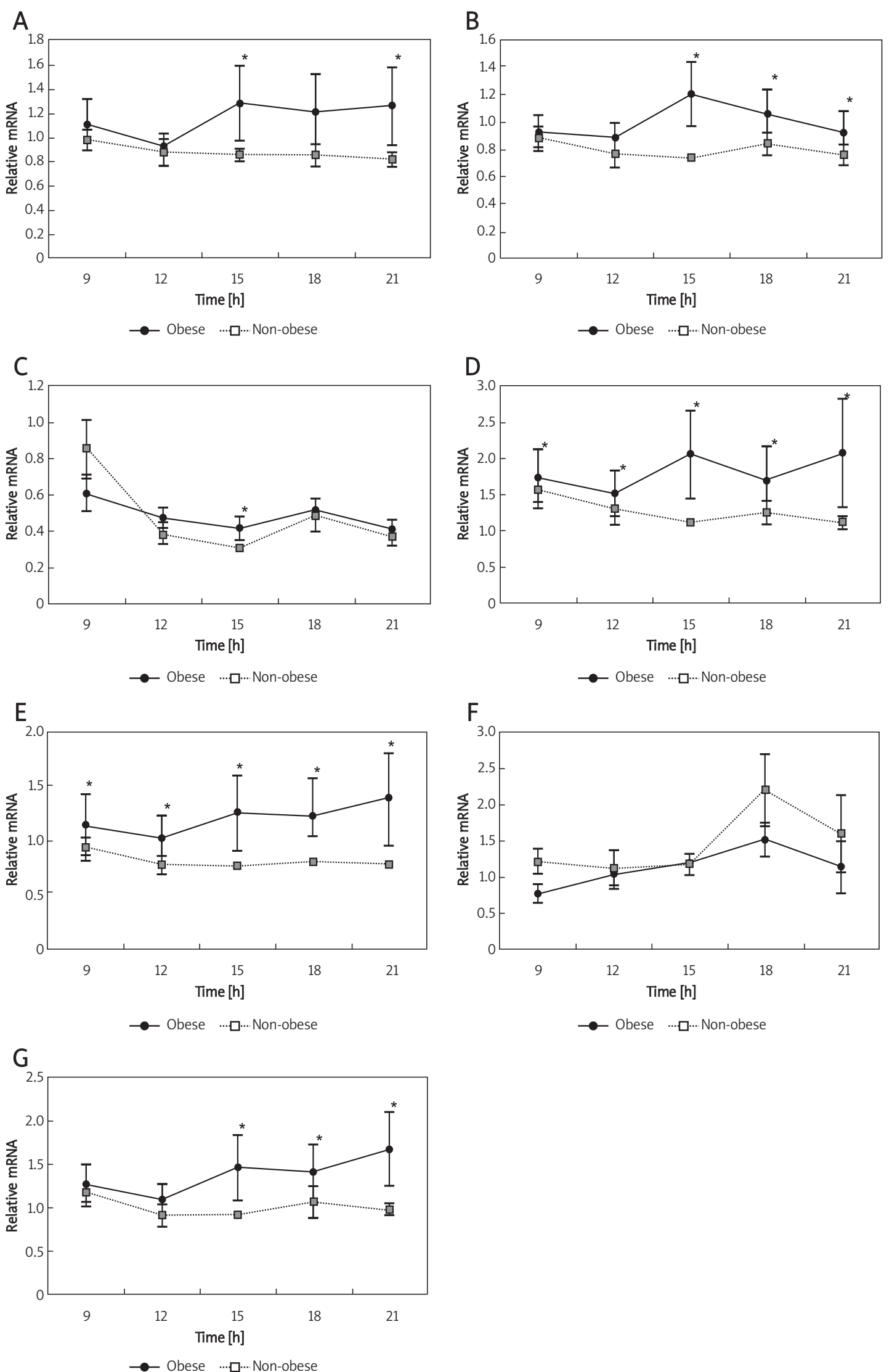

Figure 4. Expression profile variation of Bmal1 (A), Per1 (B), Per2 (C), Cry1 (D), Cry2 (E), SREBP1 (F) and Rev-Erba (G) in peripheral blood mononuclear cells from obese (solid line) and non-obese controls (dashed line) 
Studies that have compared two or more tissues have suggested that, although the genetic components of the circadian pacemaker are similar across tissues, individual genes exhibit rhythmic expression in a tissue-specific manner. Panda et al. found that only 28 genes (of more than 7000 known genes) were rhythmically expressed in both the suprachiasmatic nucleus and the liver [29]. Our current study found an altered expression of circadian clock genes in peripheral blood mononuclear cells. Peripheral blood mononuclear cells are a source of adipose tissue macrophages. In humans and rodents, adipose tissue macrophages accumulate in adipose tissue with increasing body weight and their quantity correlates with a measure of insulin resistance [32-34]. Lumeng et al. reported that diet-induced obesity leads to a shift in the activation state of adipose tissue macrophages, from a non-inflammatory state that in lean animals may protect adipocytes against inflammation, to a proinflammatory state that contributes to insulin resistance [35]. From these observations, it is possible that there is a relationship between peripheral blood mononuclear cell clock gene variation and adipose tissue gene expression.

CLOCK/BMAL1 drives translocation through E-boxes located within the promoter of various target genes including Per1, Per2, Cry1 and Cry2. When Per and Cry are translocated, they heterodimerize, translocate to the nucleus, and repress transcriptional activity at E-boxes. Interestingly, circadian variation of Per1 in human peripheral mononuclear cells in obese subjects did not appear to be linked with the circadian variation of other clock genes. This result could indicate that Per1 plays some unknown but unique role in the circadian regulation of gene expression in human peripheral mononuclear cells.

SREBP1 and REV-ERB $\alpha$ were also found to be upregulated, and their expression also oscillated in obese subjects. The E-box is known to exist in the promoter region of several genes that are involved in synthesis of fatty acids such as SREBP1 and REV-ERB $\alpha$. Bmal1 may play a role in the synthesis of fatty acids by interacting with these genes.

In conclusion, the expression patterns of circadian rhythm-related genes in peripheral blood mononuclear cells showed marked variation in expression profile, suggesting their usefulness in human circadian rhythm research. Differences existed in the expression profile variation of these genes between the obese and non-obese groups, suggesting an association between the onset/aggravation of obesity, and circadian rhythm-related gene expression. This work reveals the variability of clock gene expression profiles from peripheral mononuclear cells from both obese and non-obese subjects, with evidence for two distinct chronotypes, and suggests a contribution of these chronotypes in fat accumulation in humans.

\section{Acknowledgements}

This work was supported in part by a Grant-inAid for Culture to Nihon University from the Ministry of Education, Science, Sports, and Culture of Japan (SS, TU) and a High-Tech Research Center grant from the Japanese Ministry of Education, Culture, Sports, Science and Culture to Nihon University (YM, TU).

\section{References}

1. Allada R, Emery P, Takahashi JS, Rosbash M. Stopping time: the genetics of fly and mouse circadian clocks. Annu Rev Neurosci 2001; 24: 1091-119.

2. Reppert SM, Weaver DR. Molecular analysis of mammalian circadian rhythms. Annu Rev Physiol 2001; 63: 647-76.

3. Reppert SM, Weaver DR, Cassone VM, Godson C, Kolakowski LF Jr. Melatonin receptors are for the birds: molecular analysis of two receptor subtypes differentially expressed in chick brain. Neuron 1995; 15: 1003-15.

4. Meijer JH, Rietveld WJ. Neurophysiology of the suprachiasmatic circadian pacemaker in rodents. Physiol Rev 1989; 69: 671-707.

5. Turek FW. Circadian neural rhythms in mammals. Annu Rev Physiol 1985; 47: 49-64.

6. Balsalobre A, Brown SA, Marcacci L, et al. Resetting of circadian time in peripheral tissues by glucocorticoid signaling. Science 2000; 289: 2344-7.

7. Balsalobre A, Damiola F, Schibler U. A serum shock induces circadian gene expression in mammalian tissue culture cells. Cell 1998; 93: 929-37.

8. Mcnamara P, Seo SP, Rudic RD, Sehgal A, Chakravarti D, Fitzgerald GA. Regulation of CLOCK and MOP4 by nuclear hormone receptors in the vasculature: a humoral mechanism to reset a peripheral clock. Cell 2001; 105: 877-89.

9. Storch KF, Lipan O, Leykin I, et al. Extensive and divergent circadian gene expression in liver and heart. Nature 2002; 417: 78-83.

10. Yamazaki S, Numano R, Abe $M$, et al. Resetting central and peripheral circadian oscillators in transgenic rats. Science 2000; 288: 682-5.

11. Duffield GE, Best JD, Meurers BH, Bittner A, Loros JJ, Dunlap JC. Circadian programs of transcriptional activation, signaling, and protein turnover revealed by microarray analysis of mammalian cells. Curr Biol 2002; 12: 551-7.

12. Darlington TK, Wager-Smith K, Ceriani MF, et al. Closing the circadian loop: CLOCK-induced transcription of its own inhibitors per and tim. Science 1998; 280: 1599-603.

13. Gekakis N, Staknis D, Nguyen HB, et al. Role of the CLOCK protein in the mammalian circadian mechanism. Science 1998; 280: 1564-9.

14. Mohamed M, Gad G, Ibrahim H, et al. Cord blood resistin and adiponectin in term newborns of diabetic mothers. Arch Med Sci 2010; 6: 558-66.

15. Tatli E, Aktoz M, Altun A. Do plasma leptin levels predict diastolic dysfunction in patients with hypertension? Arch Med Sci 2009; 5: 342-6.

16. Ahren B. Diurnal variation in circulating leptin is dependent on gender, food intake and circulating insulin in mice. Acta Physiol Scand 2000; 169: 325-31. 
17. Pickavance L, Tadayyon M, Williams G, Vernon RG. Lactation suppresses diurnal rhythm of serum leptin. Biochem Biophys Res Commun 1998; 248: 196-9.

18. Calvani M, Scarfone A, Granato L, et al. Restoration of adiponectin pulsatility in severely obese subjects after weight loss. Diabetes 2004; 53: 939-47.

19. Yildiz BO, Suchard MA, Wong ML, Mccann SM, Licinio J. Alterations in the dynamics of circulating ghrelin, adiponectin, and leptin in human obesity. Proc Natl Acad Sci U S A 2004; 101: 10434-9.

20. Kudo T, Akiyama M, Kuriyama K, Sudo M, Moriya T, Shibata $S$. Night-time restricted feeding normalises clock genes and Pai-1 gene expression in the $\mathrm{db} / \mathrm{db}$ mouse liver. Diabetologia 2004; 47: 1425-36.

21. Shimba S, Ishii N, Ohta Y, et al. Brain and muscle Arnt-like protein-1 (BMAL1), a component of the molecular clock, regulates adipogenesis. Proc Natl Acad Sci U S A 2005; 102: $12071-6$.

22. Bjarnason GA, Jordan RC, Wood PA, et al. Circadian expression of clock genes in human oral mucosa and skin: association with specific cell-cycle phases. Am J Pathol 2001; 158: 1793-801.

23. Teboul M, Barrat-Petit MA, Li XM, et al. Atypical patterns of circadian clock gene expression in human peripheral blood mononuclear cells. J Mol Med 2005; 83: 693-9.

24. Tahira Y, Fukuda N, Endo M, et al. Transforming growth factor-beta expression in cardiovascular organs in strokeprone spontaneously hypertensive rats with the development of hypertension. Hypertens Res 2002; 25: 911-8.

25. Fukuya H, Emoto N, Nonaka H, Yagita K, Okamura H, Yokoyama M. Circadian expression of clock genes in human peripheral leukocytes. Biochem Biophys Res Commun 2007; 354: 924-8.

26. Kusanagi $H$, Hida A, Satoh $K$, et al. Expression profiles of 10 circadian clock genes in human peripheral blood mononuclear cells. Neurosci Res 2008; 61: 136-42.

27. Takata M, Burioka N, Ohdo S, et al. Daily expression of mRNAs for the mammalian Clock genes Per2 and clock in mouse suprachiasmatic nuclei and liver and human peripheral blood mononuclear cells. Jpn J Pharmacol 2002; 90: 263-9.

28. Ripperger JA, Shearman LP, Reppert SM, Schibler U. CLOCK, an essential pacemaker component, controls expression of the circadian transcription factor DBP. Genes Dev 2000; 14: 679-89.

29. Panda S, Antoch MP, Miller BH, et al. Coordinated transcription of key pathways in the mouse by the circadian clock. Cell 2002; 109: 307-20.

30. Rudic RD, Mcnamara P, Curtis AM, et al. BMAL1 and CLOCK, two essential components of the circadian clock, are involved in glucose homeostasis. PLoS Biol 2004; 2: e377.

31. Turek FW, Joshu C, Kohsaka A, et al. Obesity and metabolic syndrome in circadian Clock mutant mice. Science 2005; 308: 1043-5.

32. Cancello R, Henegar C, Viguerie N, et al. Reduction of macrophage infiltration and chemoattractant gene expression changes in white adipose tissue of morbidly obese subjects after surgery-induced weight loss. Diabetes 2005; 54: 2277-86.

33. Weisberg SP, Mccann D, Desai M, Rosenbaum M, Leibel RL, Ferrante AW Jr. Obesity is associated with macrophage accumulation in adipose tissue. J Clin Invest 2003; 112: 1796-808.

34. Xu H, Barnes GT, Yang Q, et al. Chronic inflammation in fat plays a crucial role in the development of obesity-related insulin resistance. J Clin Invest 2003; 112: 1821-30.
35. Lumeng CN, Bodzin JL, Saltiel AR. Obesity induces a phenotypic switch in adipose tissue macrophage polarization. J Clin Invest 2007; 117: 175-84. 